\title{
Dolo Eventual X Culpa Consciente nos Resultados Lesivos Advindo dos Crimes de Trânsito (Racha)
}

\section{Camila Austregésilo Diniz Raquel Moura da Cruz Soares}





\section{Dolo Eventual X Culpa Consciente nos Resultados Lesivos Advindo dos Crimes de Trânsito (Racha)}

\section{œ INTRODUÇÃO}

O Brasil é um dos países que apresenta os piores índices de violência no trânsito, justificando, assim, a criação de novos crimes e punição mais severa para aqueles já existentes no Código Penal pelo Código de Trânsito Brasileiro, fazendo uma ressalva aos exageros do mesmo. Almejando uma maior punição aos crimes de trânsito, o art.303 estabelece uma pena para a lesão corporal culposa cometida na condução de veículo automotor maior do que a estabelecida pelo Código Penal para a lesão corporal dolosa (ainda que no tipo simples).

Antes da vigência do Novo Código de Trânsito, o ‘racha’ era enquadrado como contravenção penal, sendo punido atualmente, tanto como infração administrativa gravíssima, com a suspensão ou proibição de se obter a permissão ou habilitação para dirigir veículo automotor, quanto infração penal, com a pena de detenção de seis meses a dois anos, regulada pelo CTB.

\section{$\infty$ CUlpa}

\subsection{Conceito}

Na definição de Julio Fabrini Mirabete ${ }^{1}$, culpa é: “A conduta humana voluntária (ação ou omissão) que produz resultado antijurídico não querido, mas previsível, e excepcionalmente previsto, que podia, com a devida atenção, ser evitado”. Podemos observar, em tal definição, os seguintes elementos:

${ }^{1}$ Apud Rogério Greco. Curso de Direito Penal, p.213. 


\subsubsection{A conduta humana voluntária, comissiva (um fazer) ou omissiva (abster-se de agir)}

Para a caracterização de qualquer crime se faz necessária a presença da conduta humana e voluntária (pois, na falta desta, teríamos a coação física recaindo na atipicidade, ausência de conduta), sendo que a conduta culposa consiste quase sempre em uma finalidade lícita ou juridicamente irrelevante para o âmbito penal. Na conduta culposa, o agente, além de não conseguir atingir o seu objetivo por empregar de forma inadequada os meios utilizados, gera um resultado lesivo não querido.

\subsubsection{Inobservância do dever objetivo de cuidado}

Consiste em regras comportamentais, ou seja, regras de condutas (expressas ou não) impostas a todos que vivem em sociedade. Quando se diz que o agente se utiliza, na conduta culposa, de meios inadequados para atingir a sua finalidade, quer-se dizer que ele não teve a cautela necessária na prática de seu ato, justamente por infringir tais regras (seja de maneira imprudente, negligente ou imperita). Por exemplo: uma mãe que deixa ao alcance de seus filhos objetos cortantes, como uma faca de cozinha. Nesse caso, percebemos que a periculosidade da conduta existe independentemente de uma norma escrita.

\subsubsection{Imprudência}

A imprudência é uma conduta positiva (comissiva) precipitada, sem observar a cautela necessária descrita pela norma ou inerente à própria razoabilidade. A norma diz que o agente deve abster-se de determinada ação, no entanto, vem a realizá-la. Lembrando que a imprudência ocorre concomitantemente ao evento danoso (pois sem o evento, não há que se falar em responsabilidade).

\subsubsection{Negligência}

A negligência é uma conduta negativa (omissiva). Quando há uma norma impondo a ação, o agente se abstém dela, permanecendo na inércia. É esta que acaba por causar o resultado. Por exemplo: um motorista não verifica os freios do carro, que vêm a falhar quando acionados, causando o atropelamento de um transeunte. Às vezes, essa omissão chega a ser tão relevante, que o legislador criou um tipo especial, a omissão imprópria (art.13, §2 ${ }^{\circ}$ ). Esta ocorre quando o agente tinha o dever legal de agir para evitar o resultado, e não apenas um dever moral. Por exemplo: um pai vê seu filho se afogando e, podendo agir, assiste inerte à morte da criança. 


\subsubsection{Imperícia}

Luiz Regis Prado² define imperícia como: "Vem a ser a incapacidade, a falta de conhecimentos técnicos precisos para o exercício de profissão ou arte. É a ausência de aptidão técnica, de habilidade, de destreza ou de competência no exercício de qualquer atividade profissional. Pressupõe a qualidade de habilitação para o exercício profissional (a falta de habilidade no conduzir o veículo (motorista profissional); não saber praticar uma intervenção cirúrgica ou prescrever um medicamento (para o médico). Havendo imperícia, fora do âmbito profissional, a culpa é atribuída ao agente a título de imprudência ou de negligência”.

\subsubsection{Resultado lesivo}

Tem que haver, para a caracterização do crime culposo, a efetiva lesão ao bem jurídico tutelado, pois, ainda que a conduta seja imprudente, negligente ou imperita, se ela não causar dano real, a conduta não poderá ser considerada criminosa por faltar um requisito da tipicidade, que é o resultado (que, no crime culposo, é naturalístico, modificando o mundo exterior). Cumpre lembrar, também, que este não é querido nem assumido (pois teríamos o dolo direito e o dolo eventual, respectivamente). Por exemplo: um padre, atrasado para celebrar uma missa, dirige em alta velocidade para chegar à igreja a tempo. Em seu trajeto, atropela um transeunte que atravessava a rua na faixa de pedestres. A conduta do padre gerou um resultado lesivo, não querido e nem assumido por ele, sendo imputado o fato ao agente a título culposo. Situação diversa é aquela em que o padre atinge a sua finalidade (chegar à igreja) sem ocasionar nenhum resultado danoso. Nesse caso, apesar de sua conduta ser arriscada, será penalmente atípica, infringindo tão somente às regras de trânsito, decorrendo do princípio da intervenção mínima, em que só se deve criar tipo penal quando a conduta for realmente relevante.

\subsubsection{Nexo de causalidade}

Tem que haver um liame, um nexo de causalidade entre a conduta culposa do agente (que não observa seu dever de cuidado) e o resultado lesivo, isto é, a conduta culposa tem que ser causa direta do resultado.

\subsubsection{Previsibilidade}

Segundo Nelson Hungria3: "Existe previsibilidade quando o agente, nas circunstâncias em que se encontrou, podia, segundo a experiência

2 In Curso de Direito Penal Brasileiro, p. 231.

${ }^{3}$ Apud Rogério Greco. Curso de Direito Penal, p. 217. 
geral, ter-se representado, como possíveis, as conseqüências do seu ato". Essa idéia, expressada por Hungria, corresponde à previsibilidade objetiva, em que, na análise da situação concreta, substitui-se a inteligência do agente pela inteligência mediana, de um homem normal, que se utilizaria naquela situação de uma atenção ordinária. Se verificarmos que mesmo assim não haveria capacidade de previsão, escaparia do âmbito da previsibilidade, recaindo no caso fortuito ou força maior, não sendo imputada a culpa ao agente, por faltar a tipicidade quanto à conduta.

Em contrapartida, há a previsibilidade subjetiva, a qual analisa a possibilidade de previsão, em concreto, do agente, ou seja, suas condições particulares, limitações e experiências (e não as do homem mediano). Quem adota essa idéia critica a previsibilidade objetiva por não verificar as circunstâncias reais. Porém, essa crítica não observa que a subjetividade não está sendo esquecida, apenas adiada para que seja verificado na culpabilidade, terceiro elemento caracterizador do crime.

\subsubsection{Tipicidade}

É a descrição legal da conduta (Exemplo: “matar alguém”, significando tirar a vida de outrem). Pelo princípio da legalidade, orientador do Direito Penal, não há crime sem lei anterior que o defina, e ninguém é obrigado a fazer ou deixar de fazer algo, senão em virtude de lei. Entretanto, como as condutas tipificadas são presumidamente dolosas, pela teoria finalista da ação, é preciso que as condutas culposas tenham previsão legal expressa (excepcionalidade dos crimes culposos).

\subsection{ESPÉCIES}

\subsubsection{Culpa consciente (ou com representação)}

Na lição de Rogério Greco ${ }^{4}$ é: “aquela em que o agente, embora prevendo o resultado, não deixa de praticar a conduta acreditando, sinceramente, que este resultado não venha a ocorrer. O resultado, embora previsto, não é assumido ou aceito pelo agente, que confia na sua não-ocorrência”.

\subsubsection{Culpa inconsciente (em estrito senso, sem representação ou comum)}

É aquela em que o resultado, embora previsível, não foi previsto pelo agente. Este transgride, sem saber, o cuidado objetivo.

\footnotetext{
${ }^{4}$ Op.cit., p. 223.
} 


\subsubsection{Culpa própria}

É a culpa comum, ocasionada por negligência, imprudência ou imperícia (artigo 18, II, do Código Penal).

\subsubsection{Culpa imprópria (por assimilação, por extensão ou equiparação)}

Ocorre nas descriminantes putativas. Por erro justificável pelas circunstâncias o agente, intencionalmente, causa um resultado lesivo. Porém, responde por crime culposo, pois a sua conduta seria lícita se as circunstâncias existissem de fato. Por exemplo: uma pessoa está assistindo a um filme no cinema quando alguém grita que o local está sendo incendiado. $\mathrm{O}$ agente, pensando agir em estado de necessidade, lesiona o segurança do local que está na porta, inviabilizando a sua saída. Se o erro for vencível (ou inescusável), e houver previsão expressa a título de culpa, o agente responderá por crime culposo. Porém, se o erro for invencível (ou escusável), a conduta será atípica, um indiferente penal.

Segundo o artigo 20, §1º do Código Penal:

"É isento de pena o agente que, por erro plenamente justificável pelas circunstâncias, supõe situação de fato que, se existisse, tornaria a ação legítima. Não há isenção de pena quando o erro deriva de culpa e o fato é punível como crime culposo".

\subsection{CoMPENSAÇÃo E CONCORRÊNCIA DE CULPAS}

Dois agentes, cada qual na direção de seu automóvel, de forma imprudente, colidem seus veículos. Nesse acidente, somente os agentes, motoristas condutores dos aludidos veículos, saíram levemente feridos.

Não haverá compensação de culpas, ou seja, não é porque ambos agiram com culpa, que nenhum deles será punido. Nesse caso, haverá a concorrência de culpas, em que ambos responderão pelo crime a título culposo na medida de sua culpabilidade. Há ainda uma outra observação a se fazer: se a culpa for exclusivamente da vítima, não há que se falar em punição para o agente, pois ninguém responde por um crime se não tiver agido ao menos com culpa (princípio da culpabilidade ou responsabilidade subjetiva), já que não adotamos a responsabilidade objetiva. 


\section{$\checkmark$ Dolo}

\subsection{ConCEITO DE CRIME DOLOSO}

O Código Penal Brasileiro faz menção ao tipo doloso em seu artigo 18, inciso I, ao dizer: "doloso, quando o agente quis o resultado ou assumiu o risco de produzi-lo”. Giuseppe Bettiol, citado na obra de Cornélio José Holanda, esclarece que: "Há efectivamente legislações em que os limites do dolo e da culpa não estão, de facto, estabelecidos no código, sendo confiada à doutrina a tarefa de fazê-lo”.

O dolo abrange o fim visado pelo agente, os meios empregados e as conseqüências do ato. Por exemplo: Alguém quer matar outrem e, para isso, coloca no avião em que ele vai viajar uma bomba. Essa conduta demonstra dolo também na morte dos outros passageiros.

\subsection{TEORIAS}

Pela teoria da representação, age com dolo aquele que simplesmente representou mentalmente o resultado lesivo, ou seja, aquele que previu como possível sua ocorrência.

Pela teoria da vontade, o agente age com dolo pelo simples fato de querer praticar o crime, ou seja, ter vontade de realizar a conduta descrita no tipo penal.

E por fim, pela teoria do assentimento (ou consentimento), o agente age com dolo quando prevê a possibilidade do resultado lesivo advindo de sua conduta, assumindo o risco de produzi-lo, ou seja, aceitando-o, pois ao prosseguir em sua conduta, demonstra sua indiferença às conseqüências danosas decorrentes da mesma.

\subsection{ANÁlise do CONCEITO}

A análise da relação entre a vontade e os elementos objetivos é que definirá de que espécie de dolo se trata a questão.

3.3.1. Se o agente realiza uma ação com o fim de determinado resultado, tem-se o dolo direito. Por exemplo: Alguém quer matar outrem e, para tanto, desfere-lhe três tiros. Percebe-se, nesse exemplo, que, além da vontade de realizar o fato típico (matar alguém), o agente se utilizou de mecanismos eficazes. Estes são de grande importância, até porque, se a tentativa não se consumar por ineficácia absoluta do meio ou por absoluta impropriedade do objeto, estaremos diante de um crime impossível, ainda 
que houvesse a intenção. Por exemplo: alguém quer matar outrem (aspecto volitivo) com garapa de açúcar. A não ser que a suposta vítima seja diabética, o resultado é impossível de ser alcançado.

3.3.2. Dolosa é também considerada a conduta em que o agente assumiu o risco de produzir o resultado (dolo eventual). "Significa que o autor considera seriamente como possível a realização do tipo legal e se conforma com ela" ${ }^{5}$. Luiz Regis Prado ${ }^{6}$, adotando a teoria da representação, complementa: "O agente conhece a probabilidade de que sua ação realize o tipo. O que caracteriza esse espécie de dolo éo elemento cognitivo (representação de um possível resultado)”.

O nosso Código Penal, contudo, não disciplina com este embasamento. Quando, em seu artigo 18, I, diz que o crime é doloso quando o agente quer produzir o resultado, adota-se a teoria da vontade; e na segunda parte do mesmo artigo, quando alude que o crime é doloso quando o agente assume o risco de produzir o resultado, adota-se a teoria do assentimento (ou consentimento), que, segundo Mirabete ${ }^{7}$ : “faz parte do dolo a previsão do resultado a que o agente adere, não sendo necessário que ele o queira" (apesar de nosso entendimento se guiar pelo Aníbal Bruno, quando ele diz que prever o resultado e não absterse da conduta é uma forma de querer).

Na verdade, a teoria do assentimento abriga a teoria da representação.

Cumpre lembrar que o dolo, no ordenamento jurídico atual, está presente na tipicidade, juntamente com o nexo causal, o resultado e a tipicidade formal (para os que não concordam com a tipicidade conglobante, do tipo do injusto do Zaffaroni). Isso porque se adota a teoria finalista da ação, onde as ações são dirigidas a uma finalidade (acolhendo o dolo natural). Por exemplo: uma pessoa está em uma loja e, ao ir embora, leva por engano a bolsa de uma cliente da loja, deixando a sua no local. Não existe furto por engano. Nesse caso específico, como não existe previsão expressa da modalidade culposa, o furto só existe se tiver havido dolo. Caso contrário, essa conduta será um indiferente penal, uma conduta atípica.

${ }^{5}$ Jescheck apud Luiz Regis Prado. Curso de Direito Penal Brasileiro, v.I, p.225.

${ }^{6}$ Luiz Regis Prado. Curso de Direito Penal Brasileiro, v.I, p.225.

${ }^{7}$ Op. cit., v.I, p.139. 
Tudo isso é para dizer que o dolo, que hoje está incluído na tipicidade, já fez parte da culpabilidade. Então, no caso citado, a conduta seria típica (se enquadraria formalmente no tipo legal do furto) e antijurídica, mas não seria culpável.

O professor Mirabete ${ }^{8}$ defende, com propriedade, a tese de que no dolo eventual:

“A vontade do agente não está dirigida para a obtenção do resultado; o que ele quer é algo diverso, mas, prevendo que o evento possa ocorrer, assume assim mesmo o risco de causálo. Essa possibilidade de ocorrência do resultado não o detém, e ele pratica a conduta, consentindo no resultado”.

Inclui, ainda, como exemplo de conduta realizada com dolo eventual a participação de disputas automobilísticas não autorizadas em via pública (“racha”), ocasionando morte.

Se uma pessoa empurra uma mulher que está grávida de oito meses (uma gravidez notória, portanto) na escada, não pode alegar culpa no abortamento, pois não há dúvida de que ele agiu ao menos com dolo eventual. Da mesma forma é o racha que causa um homicídio. Não se pode negar que o agente assumiu o risco de produzir o evento lesivo, agindo, portanto, com dolo eventual.

O dolo eventual é algo tão sério que o Mirabete ainda afirma que "age com dolo eventual o agente que, na dúvida a respeito de um dos

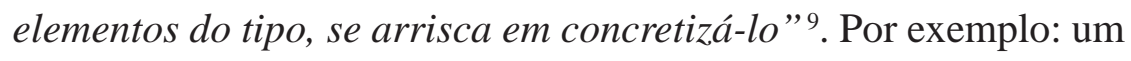
homem pratica conjunção carnal com uma menina que ele tem dúvida se é maior ou menor de 14 anos. Apurados os fatos, verifica-se que a menina tinha menos de 14 anos. O agente não será punido por sedução (art. 217, cuja pena varia de 2 a 4 anos), mas por estupro (art. 213, cuja pena varia de 6 a 10 anos), e com violência presumida (segundo o art. 224, também do Código Penal).

Situação diversa é se o agente, por erro, tem certeza de que a vítima é maior de 14 anos. Nesse caso, ele teve dolo (direto) no crime de sedução, crime pelo qual responderá.

${ }^{8}$ Op. cit. ,v.I, p.141.

${ }^{9}$ idem. 


\subsection{ESPÉCIES DE DOLO}

Na doutrina majoritária, tem-se o dolo direto e o dolo eventual. Contudo, é preciso que sejam também destacadas as outras classificações:

\subsubsection{Dolo direto (imediato ou determinado)}

Quando o agente quis o resultado e se utilizou de mecanismos eficazes para tanto. Por exemplo: alguém quis matar outrem e, para tanto, o atropelou.

\subsubsection{Dolo alternativo}

Quando o agente, como diz Mirabete, quer, entre dois ou mais resultados (matar ou ferir, por exemplo), qualquer um deles. É uma espécie do gênero dolo indireto ou indeterminado, pois não direciona sua conduta a um só resultado.

\subsubsection{Dolo eventual}

Quando o agente não quis o resultado diretamente, mas assumiu o risco de produzi-lo.

\subsubsection{Dolo de dano}

O agente tem intenção de provocar efetiva lesão ao bem jurídico protegido pela norma penal incriminadora. Exemplos: art. 121 (animus necandi) e art. 155 (animus dominus) do Código Penal.

\subsubsection{Dolo de perigo}

Há intenção de expor o bem jurídico tutelado a perigo de dano. O dano é potencial e não real, podendo vir ou não a acontecer devido à situação perigosa. Exemplos: art. 308 do Código de Trânsito Brasileiro, que trata do "racha”; art. 132 do Código Penal (expor a vida ou a saúde de outrem).

\subsubsection{Dolo genérico}

"Vontade de realizar o fato descrito na lei, em seu núcleo" (matar, subtrair etc.), sem uma finalidade específica ${ }^{10}$.

\subsubsection{Dolo específico}

"Vontade de realizar o fato com um fim especial" (exemplos: fim libidinoso; de obter vantagem indevida etc.).

\subsubsection{Dolo geral}

É o caso em que o agente, supondo ter conseguido o resultado pretendido, pratica nova ação que, esta sim, vem a resultar no evento lesivo. Rogério $\mathrm{Greco}^{11}$, ao tratar do tema, aborda que:

${ }^{10}$ Julio Fabrini Mirabete. Manual de Direito Penal. V. I, p. 144.

${ }^{11}$ Op.cit., parte geral, p. 207. 
“É o caso, sempre citado pelos doutrinadores, do agente que, após desferir golpes de faca na vítima, supondo-a morta, joga o seu corpo em um rio, vindo esta, na realidade, a falecer por afogamento".

Por seu turno, Mirabete ${ }^{12}$ defende que:

“Responderá ele por homicídio doloso consumado em decorrência do denominado dolo geral, quando, tecnicamente, haveria tentativa de homicídio seguida de homicídio culposo".

\section{$\checkmark$ Dolo Eventual X Culpa Consciente}

Há, entre essas duas espécies, um traço em comum: a previsibilidade do resultado antijurídico. Entretanto, no dolo eventual o agente assume o risco de produzir o resultado, o que não ocorre na culpa consciente, em que o agente tem firme convicção de que o resultado não ocorrerá. É por isso que ele não se abstém de sua conduta, demonstrando que se importa com a ocorrência do resultado.

Perceba que no racha, demonstrando a existência do dolo eventual, o agente prefere arriscar a concretização do evento danoso a parar a conduta. Cumpre enfatizar que a vontade não se dirige diretamente ao resultado, mas indiretamente, já que é indiferente à ocorrência do evento, pouco importando se o mesmo venha a se concretizar. É importante dizer isso, pois algumas pessoas, querendo afastar o dolo, dizem que não há, no racha, consciência e vontade de realizar o fato típico. Porém, com isso, não se lembram, ou fingem não lembrar, que o próprio Código Penal menciona, em seu artigo 18, inciso I, que o crime é doloso quando o agente quis o resultado (dolo direto) ou assumiu o risco de produzi-lo (dolo eventual). Se dolo pode ser também a anuência ou aceitação do resultado, não se faz essencial a consciência e vontade de realizar o fato típico.

É evidente que entre o dolo eventual e a culpa consciente há um limite muito estreito, tanto no âmbito penal (já comentado) como no processual (no que diz respeito à prova). É muito difícil provar o dolo eventual em uma conduta, pois isso é algo muito subjetivo sendo uma ilusão achar que o agente se autoincriminará a título de dolo eventual.

${ }^{12}$ Op.cit., v.I, p. 144. 
É sabido também que existe a máxima do in dubio pro reo (na dúvida beneficia-se o réu). Por exemplo: Duas pessoas atiram, sem ser em concurso, em uma terceira, inimiga comum das agentes. A vítima veio a falecer, porém foi comprovado que apenas um dos tiros foi responsável pelo evento morte, sendo impossível constatar de qual arma saiu o tiro. Na dúvida de quem seja a responsável pelo resultado (homicídio), aplicar-se-á às duas a tentativa de homicídio, apesar deste ter sido consumado por apenas uma delas.

Porém, algumas pessoas têm uma visão distorcida dessa máxima, pois muitas vezes partem de uma premissa falsa: que determinada conduta é duvidosa. Por exemplo: uma mulher está grávida de oito meses (portanto, uma gravidez notória). Uma pessoa a empurra em uma escada, causando o abortamento da mulher. O agente pode jurar que não teve intenção (porque ele não é obrigado a fazer prova contra si mesmo), mas a conduta dele é nitidamente dolosa, ao menos na modalidade eventual. Muitos podem dizer: "na dúvida beneficia-se o réu. Então, sem saber se a conduta é culposa ou dolosa, pune-se com a culposa”. Porém, entendemos de forma diversa: a dúvida não está em se a conduta é dolosa ou culposa, mas se o dolo é direto ou eventual.

\subsection{NOSSO ENTENDIMENTO ACERCA DOS RESULTADOS} ADVINDOS DOS CRIMES DE TRÂNSITO

A despeito do tema, Cornélio José Holanda ${ }^{13}$ indaga: "Como saber se o sujeito ativo aceitou a possibilidade de ocasionar o evento danoso? Somente pela análise da conduta anterior e da conduta concomitante ao evento será possível identificar a anuência ao resultado". Assumir o risco de determinado evento lesivo é ser indiferente quanto a esse resultado. Essa indiferença (e o descaso) é refletida, principalmente, pela conduta do agente.

As condutas anteriores (nos crimes de trânsito) são aquelas que o agente realiza antes de assumir a condução do veículo. Dentre elas, podemos citar: não verificar as condições em que se encontram os freios, não trocar os pneus desgastados (carecas), dirigir sem habilitação ou permissão etc. Exige-se a concomitância de dois ou mais elementos para uma maior certeza de configuração do dolo eventual. Ainda assim, analisando somente a conduta anterior, como não possuir habilitação ou permissão para dirigir, os tribunais já configuraram a presença do dolo eventual. Uma pessoa

\footnotetext{
${ }^{13}$ In: O dolo eventual no homicídio e na lesão corporal no trânsito, p. 80.
} 
que conhece sua inaptidão e, mesmo assim, assume a condução de um veículo, assume também o risco de ocasionar um resultado lesivo. A $3^{\text {a }}$ Câmara Criminal do TJRS julgou, tendo como Relator o des. Aristides Pedroso de Albuquerque, nesse sentido: "Deficiente físico que dirige automóvel não adaptado à sua condição, embora inabilitado, e, em alta velocidade, após derrapagem, colhe criança nas proximidades do cordão de calçada, assume o alto risco do resultado morte produzido" (DELITO DE TRÂNSITO, DOLO EVENTUAL).

As condutas concomitantes, em contrapartida, são aquelas consideradas a partir do momento em que o agente assume a direção do veículo e o põe em movimento. O principal exemplo é o ‘racha’. Já houve casos em que só o racha caracterizou o dolo eventual. O racha, a nosso ver, é a conduta que mais demonstra o descaso e a conseqüente anuência para com o evento lesivo. Isso porque essa prática, por si só, já é um ilícito penal, recaindo num risco proibido.

\title{
4.2. Participar de disputa NÃo AUTORIZAda (RACHa)
}

O artigo 308 do Código de Trânsito Brasileiro define, in verbis:

\begin{abstract}
"Participar, na direção de veículo automotor, em via pública, de corrida, disputa ou competição automobilística não autorizada pela autoridade competente, desde que resulte dano potencial à incolumidade pública ou privada.

Penas - detenção, de seis meses a dois anos, multa $e$ suspensão ou proibição de se obter a permissão ou habilitação para dirigir veículo automotor”.
\end{abstract}

\subsection{Considerações SOBRE O TIPO PENAL ACIMA}

\subsubsection{Quanto aos elementos objetivos}

Ab initio, importa fazer as seguintes distinções: A corrida é unilateral, isolada. É uma corrida contra o relógio. Trata-se do motorista que, em plena via pública, dirige em desabalada carreira para provar a potência do veículo ou para exibir-se. Na corrida, o concurso é eventual, podendo ou não existir. 
A disputa: é o “racha”, o desafio programado ou espontâneo entre dois motoristas. Ambos, num duelo alucinado e imprudente, se confrontam em via pública. Por ser indispensável a presença de duas pessoas (motoristas), o concurso de pessoas é necessário.

A competição: a disputa é coletiva, reunindo três ou mais motoristas que, em vertiginosa carreira pelas ruas da cidade, disputam o troféu da imprudência. Pelo fato da competição ter caráter coletivo, o concurso de pessoas também é necessário. Maria Elizabeth Queijo e José da Costa Junior ${ }^{14}$ definem que:

"A doutrina mais abalizada entende que a expressão competição automobilística abrange também a disputa entre condutores de outros tipos de veículos automotores além do auto-móvel, tais como motocicletas e caminhões".

\subsubsection{Quanto ao resultado naturalístico}

É um crime de mera conduta ou simples atividade. Isso porque o crime de 'racha' não exige qualquer resultado naturalístico, se contentando apenas com a conduta (ação) do agente descrita na norma. Se ocorrer algum resultado lesivo advindo do 'racha', este será tratado (se tipificado) como um crime autônomo. Difere-se do crime formal (ou de consumação antecipada) porque neste, apesar de não se exigir também qualquer resultado naturalístico, este ocorrendo, será mero exaurimento.

\subsubsection{Quanto ao elemento subjetivo}

É um crime doloso. Como os tipos penais são presumidamente dolosos, só se concebe a modalidade culposa se expressamente trazida pela norma. Em suma, se o agente não teve a intenção de praticar determinado delito, e não tendo previsão expressa da conduta como culposa, sua ação será atípica (um indiferente penal).

\subsubsection{Quanto à possibilidade do conatus (ou tentativa)}

Segundo Cornélio José Holanda ${ }^{15}$ :

“A tentativa é admissível, e poderá se configurar, por exemplo, quando os competidores são surpreendidos com

${ }^{14}$ Apud Cornélio José Holanda. O dolo eventual no homicídio e na lesão corporal no trânsito, p. 40-41.

${ }^{15}$ Op.cit., p. 41. 
os veículos alinhados e os motores em funcionamento, prontos a iniciar a disputa”.

\subsubsection{Quanto ao objeto ou bem jurídico tutelado}

A incolumidade (integridade) pública e privada, pondo em risco a integridade física dos outros condutores e dos transeuntes. Ainda segundo Cornélio Holanda ${ }^{16}$ :

"A realização de pegas ou rachas configura atividade de alto risco porque, no intento de vencer a disputa e levados pelo calor da contenda, os competidores ignoram as regras básicas do trânsito e, por desenvolverem velocidades excessivas, terão dificuldades em reagir, a tempo hábil, a qualquer obstáculo que se apresente, o que resulta, não poucas vezes, em graves acidentes".

O Pretório Excelso, a despeito da matéria, já se pronunciou em diversas oportunidades, conforme pequena coletânea abaixo:

"Homicídio doloso - Acidente de trânsito - Racha automobilístico - Reconhecimento do dolo eventual - 'A conduta social desajustada daquele que, agindo com intensa reprovabilidade ético-jurídica, participa, com o seu veículo automotor, de inaceitável disputa automobilística realizada em plena via pública, nesta desenvolvendo velocidade exagerada - além de ensejar a possibilidade de reconhecimento de dolo eventual inerente a esse comportamento do agente -, justifica a especial exasperação da pena, motivada pela necessidade de o Estado responder, grave e energicamente, à atitude de quem, em assim agindo, comete os delitos de homicídio doloso e de lesões corporais' (STF - HC - Rel. Celso de Mello - RT 733/478)" ${ }^{17}$.

“HOMICÍDIO - Desclassificação para a modalidade culposa. Inadmissibilidade. Fundada suspeita de racha. Dolo eventual. Hipótese em que o sujeito assumiu o risco

\footnotetext{
${ }^{16}$ Op.cit., p. 87.

${ }^{17}$ Luiz Regis Prado. Curso de Direito Penal Brasileiro, p. 233-234.
} 
de produzir o resultado. Circunstância que obriga o julgamento dos réus pelo Tribunal do Júri. Recurso não provido. Quem se lança numa competição automobilística de velocidade, numa cidade populosa, à custa de possibilidade de produção de um resultado lesivo, age igualmente com dolo eventual de homicídio, lesões e danos. (TJSP SER 249.440-3/5 - 5 C.Crim. - Rel. Dês. Dante Busana - J.30.11.2000)" ${ }^{18}$.

\section{Conclusão}

De tudo conclui-se pelo reconhecimento de que, na maioria dos casos, há presença do dolo eventual nas circunstâncias lesivas advindas dos crimes de trânsito, mais especificamente do “racha”.

A jurisprudência pátria, principalmente a de $1^{\mathrm{a}}$ instância ou grau, tem reconhecido o dolo eventual nas condutas típicas de homicídio e lesão corporal praticadas no trânsito. Assim o fazem com base nas circunstâncias fáticas, avaliando, principalmente, as condutas anteriores e concomitantes à condução do veículo por parte do agente.

Com o conhecimento da definição de crime culposo e crime doloso e analisando suas espécies (inclusive o dolo eventual e a culpa consciente), o conceito e as teorias, pudemos constatar a presença do dolo eventual no crime de racha.

${ }^{18}$ Cornélio José Holanda. O dolo eventual no homicídio e na lesão corporal no trânsito, p. 87. 


\section{Bibliografia}

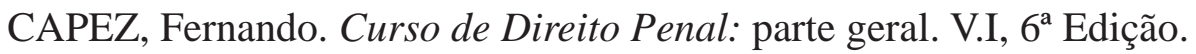
São Paulo. Saraiva, 2003.

PINHEIRO, Geraldo de Farias. Código de Trânsito Brasileiro Sistematizado. São Paulo: Juarez de Oliveira, 2001.

GRECO, Rogério. Curso de Direito Penal: parte geral. $3^{\mathrm{a}}$ ed. Rio de Janeiro: Ímpetus, 2000.

HOLANDA, Cornélio José. O Dolo Eventual no Homicídio e na Lesão Corporal no Trânsito. Fortaleza, Edições Técnicas, 2003.

JESUS, Damásio E. de. Crimes de Trânsito: anotações à parte criminal do Código de Trânsito. $4^{\mathrm{a}}$ ed. São Paulo, Saraiva, 2000.

Direito Penal. São Paulo, Saraiva, 1999.

MIRABETE, Julio Fabrini. Manual de Direito Penal. 19a ed. São Paulo. Atlas, 2003.

PRADO, Luiz Regis. Curso de Direito Penal Brasileiro: parte geral. $2^{\mathrm{a}}$ ed. São Paulo. Editora Revista dos Tribunais, 200.

ZAFFARONI, Eugenio Raúl, e PIERANGELI, José Henrique. Manual de Direito Penal Brasileiro. $5^{a}$ ed. São Paulo. Editora Revista dos Tribunais, 2004. 